\title{
Evaluasi Perilaku Wajib Pajak Badan Terhadap E-filing Sebagai Sarana Pelaporan Pajak Secara Online Dan Realtime
}

(Pada KPP Pratama Makassar Selatan)

\section{Fitriani}

Magister Akuntansi, Konsentrasi Perpajakan, Program Pascasarjana Universitas Muslim Indonesia, Makassar, Indonesia.

E-mail : nengfitriani332@yahoo.com

\begin{abstract}
ABSTRAK
FITRIANI. Evaluasi Perilaku Wajib Pajak Badan Terhadap E-filing Sebagai Sarana Pelaporan Pajak Secara Online Dan Realtime Pada KPP Pratama Makassar Selatan. (dibimbing oleh Prof. Dr. H. Abdul Rahman Mus, SE., M.Si dan Dr. H. Muhammad Su'un, SE, M.Si, AK., CA).

Penelitian ini bertujuan untuk mengetahui pengaruh perilaku wajib pajak terhadap persepsi kegunaan E-filing, persepsi kemudahan E-filing, persepsi kerumitan Efiling, terhadap penggunaan E-filing pada wajib pajak badan sebagai sarana pelaporan pajak secara online dan realtime. Dengan menggunakan Technology Acceptance Model (Davis, 1989) yaitu model yang secara luas digunakan dalam penelitian sistem informasi.

Jenis penelitian ini adalah penelitian kuantitatif. Dalam penelitian ini digunakan dua metode pengumpulan data. Pertama penelusuran data primer dan penyebaran koesioner.

Hasil penelitian ini menunjukan bahwa persepsi kegunaan berpengaruh positif terhadap penggunaan E-filing, Persepsi kemudahan berpengaruh positif terhadap penggunaan E-filing, Persepsi kerumitan berpengaruh negatif terhadap penggunaan Efiling.
\end{abstract}

Kata Kunci : Persepsi Kegunaan, Persepsi Kemudahan, Persepsi Kerumitan, Dan Penggunaan E-filing 


\begin{abstract}
ABSTRAK
FITRIANI. Evaluasi Perilaku Wajib Pajak Badan Terhadap E-filing Sebagai Sarana Pelaporan Pajak Secara Online Dan Realtime Pada KPP Pratama Makassar Selatan. (dibimbing oleh Prof. Dr. H. Abdul Rahman Mus, SE., M.Si dan Dr. H. Muhammad Su'un, SE, M.Si, AK., CA).

This study aims to determine the effect of taxpayer behavior on perception of Efiling usefulness, perception of e-filing ease, perception of E-filing complexity, on the use of E-filing in corporate taxpayer as a means of reporting taxes online and realtime. By using the Technology Acceptance Model (Davis, 1989) is a model that is widely used in information systems research E-filing.

This type of research is quantitative research. In this study used two methods of data collection. First searching of primary data and distribution of koesioner.

The results of this study indicate that the perception of utility has a positive effect on the use of E-filing, the perception of ease positively affect the use of E-filing, Perception complexity negatively affect the use of E-filing.
\end{abstract}

Keywords: perception of usefulness, perception of ease, perception of complexity, and use of e-filing. 


\section{PENDAHULUAN}

\section{LATAR BELAKANG}

Perpajakan adalah penyederhanaan sistem perpajakan sehingga administrasi perpajakan dapat dikelola seefektif dan seefisien mungkin, terlebih di negara dengan tingkat kepatuhan relatif rendah seperti di Indonesia (Setiyaji dan Amir, 2005). Modernisasi pajak melalui pelayanan perpajakan berbasis teknologi informasi yang tepat guna merupakan salah satu solusi yang tidak hanya dapat memberikan pelayanan yang cepat, berkualitas, dan handal melainkan juga mendukung terciptanya penyederhanaan sistem perpajakan dan membantu terwujudnya good governance. Seiring dengan perkembangan zaman, perkembangan teknologi juga mengalami kemajuan yang cukup pesat, terutama pada perkembangan teknologi internet. Salah satunya adalah kemajuan teknologi dalam bidang pengarsipan. Arsip elektronik bersifat lebih praktis dan memiliki tingkat resiko yang lebih kecil dari pada arsip secara manual.

Teknologi ini telah digunakan oleh berbagai instansi-instansi dan juga pelaku bisnis. Dalam bidang perpajakan kantor direktorat Jenderal Pajak telah menggunakan arsip elektronik, yang digunakan untuk mendokumentasikan semua arsip-arsipnya. Hal ini merupakan salah satu pembaruan dalam sistem perpajakan yang dilakukan oleh Direktorat Jenderal Pajak, dengan maksud untuk memudahkan, meningkatkan serta mengoptimalisasikan pelayanan kepada wajib pajak.

Dalam melaksanakan kewajiban perpajakan, Wajib pajak harus datang ke kantor pelayanan pajak ataupun dikirim melalui pos. Dengan itu maka diperlukan sumber daya manusia yang banyak dan juga tempat yang luas, serta waktu dan proses yang lambat karena dikirim secara manual. Untuk itu kantor pelayanan pajak berupaya untuk melakukan pembaharuan sistem agar kewajiban perpajakan dapat dilakukan secara online, karena dengan menggunakan fasilitas internet informasi dapat diperoleh dengan sangat cepat dan juga mudah.

Sistem administrasi yang manual ini akan meningkatkan tax compliance cost para Wajib Pajak dalam segi waktu (time Cost) untuk menjalankan sistem administrasi perpajakan, terutama pada saat pengisian SPT dan pelaporan, dikarenakan khususnya Wajib Pajak Badan harus mengalami tingkat kesulitan yang cukup tinggi ketika melakukan Pengisian SPT yang memiliki transaksi dengan jumlah yang banyak dan mengalami antrian yang cukup panjang dan lama untuk menunggu pegawai pajak melakukan perekaman data SPT yang dilaporkan, begitu juga para pegawai yang mengalami kesulitan untuk melakukan perekaman data SPT yang dilaporkan dalam jumlah yang banyak.

Menyikapi meningkatnya kebutuhan wajib pajak akan tingkat pelayanan yang semakin baik, cepat, membengkaknya biaya pemprosesan laporan pajak, dan keinginan untuk mengurangi biaya proses administransi laporan pajak menggunakan kertas, Direktorat Jenderal Pajak berusaha untuk memenuhi aspirasi Wajib Pajak dengan mempermudah tata cara pelaporan SPT baik itu SPT Masa maupun SPT Tahunan. Hal ini ditandai dengan dikeluarkannya keputusan Direktur Jenderal Pajak Nomor 47/PJ/2008 secara resmi diluncurkan produk E-filing atau Electronic Filing system yaitu sistem penyampaian surat pemberitahuan (SPT) secara elektronik yang dilakukan melalui sistem online dan realtime melalui perusahaan penyedia jasa aplikasi yang ditunjuk oleh Dirjen Pajak. Peraturan tersebut tertuang dalam perdirjen No 36/PJ/2013 tentang tata cara penyampaian SPT secara elektronik penyedia jasa Aplikasi (e-filing). 
Tujuan utama dari pelaporan e-filling adalah memangkas biaya dan waktu Wajib Pajak untuk mempersiapkan, memproses dan melaporkan Surat Pemberitahuan (SPT) ke Kantor Pajak secara benar dan tepat waktu. Sistem e-filling ini juga memberikan dukungan kepada Kantor Pajak dalam hal percepatan penerimaan Laporan Surat Pemberitahuan (SPT) dan perampingan kegiatan administrasi, pendataan dan akurasi data, distribusi serta pengarsipan Laporan Surat Pemberitahuan (SPT).

Dengan adanya kemudahan untuk memenuhi kewajiban perpajakan diharapkan dapat meningkatkan kepatuhan wajib pajak. Selain itu, transisi cara penyampaiannya dan pelaporan surat pemberitahuan (SPT) dapat memudahkan dan memberikan manfaat bagi Direktorat Jenderal Pajak (DJP) sendiri dalam pengelolaan pajak. Oleh karena itu perlu dukungan dari semua pihak secara terus-menerus agar peningkatan pelayanan kepada wajib pajak terus berjalan dengan sekaligus terciptanya administrasi perpajakan yang modern. Menurut data dari KPP Makassar Selatan semenjak sistem e-filing diterapkan di KPP makassar selatan, maka Di Tahun 2013, penerimaan pajak KPP Pratama Makassar Selatan sebesar Rp. 774.217.805.620 atau 104,2 \% dari target penerimaan sebesar Rp. 742.777.221.196 dengan pertumbuhan sebesar 38,26\% dari penerimaan tahun lalu sebesar Rp. 559.955.123.655. meningkat.

Untuk memberikan pemahaman yang lebih baik lagi kepada Wajib Pajak mengenai Pelaporan SPT Tahunan, Kantor Pelayanan Pajak (KPP) Pratama Makassar Selatan melaksanakan sosialisasi e-Filing kepada Wajib Pajak melalui Kelas Pajak. Petugas memberikan penjelasan mengenai tata cara pelaporan SPT Tahunan, serta memperkenalkan cara mudah, cepat dan aman dalam pelaporan secara online melalui eFiling. Pelaporan dulunya hanya dapat dilakukan dengan cara datang langsung ke TPT pada KPP, hal ini bisa menjadi kendala apabila Wajib Pajak yang memiliki kesibukan tersendiri sehingga menghambat kewajiban Wajib Pajak sehubungan dengan Pelaporan SPT Tahunannya. Pelaporan SPT tahunan melalui e-Filing ini mendapat respon positif dari Wajib Pajak, karena Wajib pajak bisa melaporkan SPT tahunan tanpa harus ke KPP dan waktu kerjapun tidak terganggu karena bisa dilaporkan kapan saja dan dimana saja asalkan ada koneksi internetnya dan tidak lewat jatuh tempopelaporan.

Berdasarkan latar belakang diatas, timbul keinginan peneliti untuk menguji dan menganalisis apakah Perilaku Wajib Pajak Badan (Persepsi Kegunaan, Persepsi Kemudahan, Persepsi Kerumitan) berpengaruh terhadap Penggunaan E-filing.

\section{Rumusan Masalah}

Mengacu pada uraian latar belakang di atas, maka perumusan masalah dalam penelitian ini adalah:

1. Apakah perilaku wajib pajak berpengaruh terhadap persepsi kegunaan dalam penggunaan $e$-filing?

2. Apakah perilaku wajib pajak berpengaruh terhadap persepsi kemudahan dalam penggunaan $e$-filing?

3. Apakah perilaku wajib pajak berpengaruh terhadap persepsi kerumitan (complexity) dalam penggunaan $e$-filing?

\section{Tujuan Penulisan}

1.Untuk menganalisis pengaruh perilku wajib pajak terhadap persepsi kegunaan dalam penggunaaan $e$-filing 
2.Untuk menganalisis pengaruh perilaku wajib pajak terhadap persepsi kemudahan dalam penggunaan $e$-filing

3.Untuk menganalisis pengaruh perilaku wajib pajak terhadap persepsi kerumitan dalam penggunaan $e$-filing.

\section{LANDASAN TEORI DAN PENGEMBANGAN HIPOTESIS}

\section{Perilaku Wajib Pajak Berpengaruh terhadap Persepsi Kegunaan dalam Penggunaan E-Filing}

Arikunto (2006) mengemukakan bahwa hipotsis merupakan suatu jawaban yang bersifat sementara terhdap prmasaalahan peneltin, sampai terbuti melalui data yang terkumpul.

Menurut Moskowitz dan ogel dalam(Walgito 203:54) persepsi merupakan proses yang integrated dari individu terhadap stimulus yang ditrimanya. Dengan demikian pula dapat dikemukakan bahwa persepsi merupakan proses pengorganisasian, penginterprestasin, terhadap stimulus yang diterima organisme atau individu sehingga merupakan suatu yang berarti dan merupkan integrated dalam diri individu.

Menurut kautsar Riza Salman (2007) perilaku wajib pajak adalah tingkah laku wajib pajak yang memasukkan dalam melaporkan pada waktunya informasi yang diperlukan, mengisi secara benar jumlah pajak yang terutang, dan membayar pajak pada waktunya tanpa ada tindakan paksaan.

Penelitian yang dilakukan oleh Davis (1989) menemukan bahwa hubungan persepsi kegunaan terhadap penggunaan senyatanya lebih kuat dibandingkan konstruk manapun. Szana (1996) juga menemukan hubungan yang signifikan antara dua konstruk tersebut. Sun dan Zhang (2003) telah mengkonfirmasi juga bahwa kegunaan sebagai faktor yang paling penting penerimaan penggunaan dengan sedikit pengecualian. Maka diajukan hipotesis penelitian sebagai berikut:

$\mathrm{H} 1$ = Perilaku wajib pajak berpengaruh positif terhadap Persepsi kegunaan (Perceived Usevulness) dalam penggunaan $e$-filing.

\section{Perilaku Wajib Pajak Berpengaruh Terhadap Persepsi Kemudahan Dalam Penggunaan E-filing.}

Studi yang dilakukan wiyono (2008) terhadap para wajib pajak yang telah mencoba menggunakan $e$-filing di indonesia telah menunjukan hasil bahwa persepsi kemudahan berpengaruh signifikan terhadap persepsi kegunaan tekhnologi. Jika pengguna menginteroretasikan bahwa sistem $e$-filing mudah digunakan maka pengguna sistem akan tercapai.

$\mathrm{H} 2$ = Perilaku wajib pajak berpengaruh positif terhadap Persepsi kemudahan (Perceived ease of Use) dalam penggunaan $e$-filing.

Persepsi kerumitan yang dimaksud dalam penelitian ini merupakan akibat dari inovasi sistem e-filing yang dianggap relatif mungkin sulit dipahami dan digunakan (Susanto, 2011). Untuk Variabel Persepsi Kerumitan digunakan 2 pertanyaan:

1. Menggunakan e-filing dapat menyita banyak waktu ketika mengerjakan banyak tugas

2. Hasil Penggunaan e-filing sulit untuk dipadukan dengan pekerjaan.

3. Menggunakan E-filing berbahaya bagi komputer dan data saya. 
Oleh karena itu hipotesis yang dapat diambil:

H3 = Perilaku wajib pajak berpengaruh negatif terhadap Persepsi Kerumitan (Complekxity) dalam penggunaan $e$-filing

\section{METODOLOGI PENELITIAN}

\section{Sumber Data, Populasi, dan Sampel}

Penelitian ini menggunakan data primer dan sekunder. Populasi dalam penelitian ini adalah seluruh wajib pajak badan yang terdaftar di Kantor Pelayanan Pajak Pratama Makassar Selatan. Sampel penelitian diambil berdasarkan penggunaan teknik purposive sampling.

\section{Pengembangan Instrumen}

Peneliti mengembangkan instrumen penelitian dengan mendefenisi operasionalkan variabel dan menurunkan pernyataan dari indikator. Berikut instrumen penelitian ini :

a. Persepsi Kegunaan (X1)

Persepsi kegunaan yang dimaksud dalam penelitian ini adalah persepsi tentang sejauh mana e-filing mampu memberikan manfaat bagi wajib pajak (Noviandini, 2012). Variabel persepsi dari e-filing yang memuat hal-hal sebagai berikut:

a. E-filing dapat meningkatkan efektifitas pelaporan pajak saya.

b. E-filing dapat membantu saya melakukan pelaporan pajak secara efisien.

c. E-filing dapat membantu saya melakukan pelaporan SPT tepat waktu.

d. Penggunaan $e$-filing dapat memperkecil kesalahan pelaporan pajak saya.

e. Saya merasa penggunaan $e$-filing dapat menguntungkan bagi saya.

f. Dengan adanya $e$-filing dapat mengembangkan kinerja saya.

b. Persepsi Kemudahan (X2)

Persepsi kemudahan dalam penelitian ini merupakan tingkat sejauh mana seseorang percaya bahwa dalam menggunakan sistem e-filing pengguna dapat menggunakan e-filing dengan mudah tanpa adanya hambatan dan usaha yang keras (Noviandini, 2012). Untuk melihat persepsi kemudahan dalam menggunakan $e$-filing, digunakan enam pertanyaan yang memuat hal-hal sebagai berikut:

a. Sistem $e$-filing mudah dan nyaman digunakan

b. Sistem $e$-filing mudah dipelajari oleh pengguna

c. Sangat mudah bagi pengguna untuk menjadi ahli dalam menggunakan $e$ filing

d. Akses ke server ASP (jasa penyedia aplikasi) dapat dilakukan dengan cepat, mudah dan nyaman.

e. Sistem $e$-filing dapat merespon dan memberikan konfirmasi dengan cepat.

f. E-filing sangat fleksibel bagi pengguna dalam memanfaatkan layanan pelaporan perpajakan.

\section{c. Persepsi Kerumitan (X3)}

Persepsi kerumitan (kompleksitas) yang dimaksud dalam penelitian ini merupakan akibat dari inovasi sistem e-filing yang dianggap relatif mungkin sulit untuk dipahami dan digunakan (Susanto, 2011). Untuk variabel persepsi kerumitan digunakan pertanyaan yang memuat hal sebagai berikut: 
a. Menggunakan $e$-filing dapat menyita banyak waktu ketika mengerjakan banyak tugas.

b. Hasil penggunaan $e$-filing sulit untuk dipadukan dengan pekerjaan.

c. Menggunakan E-filing berbahaya bagi komputer dan data saya

\section{d. Pengguna E-filing (Y)}

Menurut Noviandini (2012), penggunaan e-filing merupakan ukuran dari minat seseorang untuk menunjukan perilaku terhadap adanya sistem penyampaian SPT secara online (e-filing). Variabel e-filing dioperasikan dengan tiga pertanyaan terkait hal berikut:
a. Menggunakan e-filing setiakali melaporkan pajak
b. Menggunakan e-filing dimasa depan
c. Menggunakan $e$-filing karena memiliki fitur membantu pekerjaan.

\section{Metode Analisis Data}

Metode analisis data yang digunakan oleh peneliti adalah uji kualitas data (uji validitas dan uji realibilitas), uji asumsi klasik (uji normalitas data, uji multikolonieritas, dan uji heteroskedastisitas), dan uji hipotesis (uji persamaan regresi linear berganda, koefisien determinan, uji simultan, dan uji parsial).

\section{HASIL DAN PEMBAHASAN}

a. Uji reliabilitas.

Uji Reliabilitas dilakukan untuk menunjukan sejauh mana alat pengukuran dapat dipercaya. Secara umum suatu variabel dikatakan reliabilitas jika memberikan nilai cronbach alpha > 0,6 maka kuesioner penelitian tersebut dinyatakan reliable. Hasil uji reliabilitas berdasarkan tabel 5 menunjukan bahwa variabel mempunyai koefisien cronbach alpha sebesar 0,787 (X1), 0,810 (X2), 0,610 (X3) dan ),654 (Y) hal ini menunjukan bahwa koefisien cronbach alpha lebih besar dari. Dengan demikian item pengukuran pada variabel dinyatakan reliabilitas dan selanjutnya dapat digunakan dalam penelitian ini.

b. Uji Validitas

Pengujian ini dilakukan dengan cara menggunakan corrected item total corellation yaitu dengan cara mengkorelasi skor tiap item dengan skor totalnya, dengan jumlah responden 100 dan tingkat signifikansi 5\%, butir pertanyaan kuesioner dinyatakan valid jika $r_{\text {hitung }}>r_{\text {tabel }}$ dan sebaliknya. Dari penelitian ini diketahui bahwa $r_{\text {tabel }}$

\section{Uji Asumsi Klasik}

a. Uji Normalitas

Uji Normalitas data dilakukan untuk melihat bahwa suatu data terdistribusi secara normal atau tidak. Uji normalitas data dilakukan dengan menggunakan histogramstandardizet residual dengan PP plosstandardizet residual. Uji normalitas bertujuan untuk menguji variabel dependen dan independen yaitu keadilan (X1), sistem perpajakan (X2), diskriminasi(X3) terhadap Tax Evasion (Y) keduanya memiliki distribusi normal Atau tidak. 
b. Uji multikolonieritas

Uji multikolonieritas bertujuan untuk menguji apakah dalam model regresi ditemukan adanya korelasi antara variabel bebas (independen). Jika variabel independen saling berkolerasi, maka variabel-variabel tidak ortogonal. Model regresi yang baik adalah yang bebas dari multikolonieritas. Nilai cuttoff yang umum dipakai untuk menunjukan adanya multikolonieritas nilai tolerance $>0,10$ atau sama dengan nilai VIF $<10$ berdasarkan hasil pengolahan data variance infastion menunjukan bahwa nilai VIF < 10 sehingga dikategorikan bebas mulitikolonieritas artinya variabelvariabel dependen ortogonal.

c. Uji Heteroskedastisitas

Uji heteroskeditas bertujuan untuk menguji apakah dalam model regresi terjadi ketidaksamaan variance dari residual satu pengamatan ke pengamatan yang lain. Jika variance dari residual satu pengamatan ke pengamatan lain tetap, maka disebut homoskedastistas dan jika berbeda disebut heteroskedastistas. Model regresi yang baik adalah yang homoskedastistas atau tidak terjadi heteroskedastitstas.

\section{Pengujian Hipotesis}

\section{a. Analisis Regresi Linear Berganda}

\section{Coefficients ${ }^{\mathrm{a}}$}

\begin{tabular}{|c|c|c|c|c|c|c|c|}
\hline \multirow[b]{2}{*}{ Model } & \multicolumn{2}{|c|}{$\begin{array}{c}\text { Unstandardized } \\
\text { Coefficients }\end{array}$} & \multirow{2}{*}{$\begin{array}{c}\text { Standardized } \\
\text { Coefficients } \\
\text { Beta }\end{array}$} & \multirow[b]{2}{*}{$\mathrm{t}$} & \multirow[b]{2}{*}{ Sig. } & \multicolumn{2}{|c|}{$\begin{array}{l}\text { Collinearity } \\
\text { Statistics }\end{array}$} \\
\hline & B & Std. Error & & & & Tolerance & VIF \\
\hline (Constant) & 3.005 & .724 & & 4.150 & .000 & & \\
\hline $\mathrm{X} 1$ & .271 & .112 & .233 & 2.415 & .018 & .924 & 1.083 \\
\hline $\mathrm{X} 2$ & .211 & .096 & .204 & 2.193 & .031 & .996 & 1.004 \\
\hline X3 & -.297 & .132 & -.216 & -2.248 & .027 & .927 & 1.079 \\
\hline
\end{tabular}

a. Dependent Variable: Y

Hasil uji regresi linear berganda dalam penelitian ini menghasilkan rumus sebagai berikut : $\mathrm{Y}=3,005+0,271+0,211+-0,297$

\section{b. Uji koefisien determinasi $\left(\mathbf{R}^{2}\right)$}

\begin{tabular}{|l|r|r|r|c|}
\hline Model & $\mathrm{R}$ & R Square & $\begin{array}{c}\text { Adjusted R } \\
\text { Square }\end{array}$ & $\begin{array}{c}\text { Std. Error of the } \\
\text { Estimate }\end{array}$ \\
\hline 1 & $.420^{\mathrm{a}}$ & .176 & .151 & .40094 \\
\hline
\end{tabular}

a. Predictors: (Constant), X3, X2, X1

b. Dependent Variable: Y

Dari tabel di atas dapat disimpulkan bahwa nilai $\mathrm{R}$ square adalah sebesar 0,176 atau 17.6\% menunjukkan bahwa 3 variabel independen (Persepsi kegunaan, persepsi kemudahan, persepsi kerumitan) secara simultan berpengaruh terhadap variabel dependen 


\section{c. Uji signifikan parameter simultan (uji Statistik F)}

ANOVA $^{\text {b }}$

\begin{tabular}{|l|r|r|r|r|r|}
\hline Model & Sum of Squares & df & Mean Square & F & Sig. \\
\hline 1 Regression & 3.304 & 3 & 1.101 & 6.851 & $.000^{\mathrm{a}}$ \\
Residual & 15.432 & 96 & .161 & & \\
Total & 18.736 & 99 & & & \\
\hline
\end{tabular}

a. Predictors: (Constant), X3, X2, X1

b. Dependent Variable: Y

Hasil uji simultan (uji F) dalam penelitian ini menunjukkan bahwa Fhitung 6.851 dan tingkat signifikan sebesar 0.05 . Bahwa ketiga variabel independen dapat berpengaruh secara simultan terhadap penggunaan e-filing

\section{d. Uji signifikan parameter individual}

Uji t menunjukan seberapa jauh pengaruh satu variabel independen secara individual mampu memerankan variasi variabel dependen.

\begin{tabular}{|c|c|c|c|c|}
\hline Hipotesis/Variabel & $t_{\text {hitung }}$ & $t_{\text {tabel }}$ & Sig & Keterangan \\
\hline $\begin{array}{lr}\begin{array}{l}\text { Perilaku } \\
\text { berpengaruh }\end{array} & \text { pajak } \\
\text { terhadap } & \text { positif } \\
\text { kegunaan } & \text { Persepsi } \\
\text { Usevulness) } & \text { (Perceived } \\
\text { penggunaan } & \text { e-filing. }\end{array}$ & 2.415 & 1.661 & $0,018<0,05$ & $\begin{array}{l}\mathrm{H}_{0}: \text { Di tolak } \\
\mathrm{H}_{1}: \text { Di terima }\end{array}$ \\
\hline $\begin{array}{lr}\begin{array}{l}\text { Perilaku wajib } \\
\text { berpengaruh }\end{array} & \text { pajak } \\
\text { terhadap } & \text { positif } \\
\text { kemudahan } & \text { Persepsi } \\
\text { ease of } & \text { Useived } \\
\text { penggunaan } e \text {-filing. } & \text { dalam } \\
\end{array}$ & 2.193 & 1.661 & $0,031<0,05$ & $\begin{array}{l}\mathrm{H}_{0}: \text { Di tolak } \\
\mathrm{H}_{2} \text { :Di terima }\end{array}$ \\
\hline $\begin{array}{lr}\text { Perilaku wajib } & \text { pajak } \\
\text { berpengaruh } & \text { negatif } \\
\text { terhadap } & \text { Persepsi } \\
\text { Kerumitan (Complekxity) } & \text { (Calam penggunaan } \\
\text { e-filing }\end{array}$ & -2248 & 1.661 & $\overline{0}-027<0,05$ & $\begin{array}{l}\mathrm{H}_{0}: \text { Di tolak } \\
\mathrm{H}_{3}: \text { Di terima }\end{array}$ \\
\hline
\end{tabular}

\section{PEMBAHASAN}

Berdasarkan hasil penelitian yang menguji evaluasi perilaku wajib pajak terhadap E-filing sebagai sarana pelaporan pajak secara online dan realtime pada Kantor Pajak Pratama Makassar Selatan yang telah diuraikan diatas, maka ada beberapa hal yang dapat dijelaskan dalam penelitian ini, yaitu:

Hasil penelitian ini mendukung hipotesis pertama yang menyatakan perilaku wajib pajak berpengaruh positif terhadap persepsi kegunaan dalam penggunakan $e$-filing . 
E-filing memiliki pengaruh yang cukup kuat dan positif, artinya semakin tinggi persepsi kegunaan maka semakin tinggi pula penggunaan e-filing oleh Wajib Pajak Badan. Hal tersebut konsisten dengan penelitian yang dilakukan oleh Davis (1989) menemukan bahwa hubungan persepsi kegunaan terhadap penggunaan senyatanya lebih kuat dibandingkan konstruk manapun. Szana (1996) juga menemukan hubungan yang signifikan antara dua konstruk tersebut. Sun dan Zhang (2003) telah mengkonfirmasi juga bahwa kegunaan sebagai faktor yang paling penting penerimaan penggunaan dengan sedikit pengecualian. 4

Kemudahan dalam menggunakan e-filing berhubungan erat dengan kemauan wajib pajak untuk menggunakan e-filing. Dari hal tersebut diketahui bahwa konstruk kemudahan pengguna ini merupakan suatu kepercayaan tentang proses pengambilan keputusan (Jogiyanto 2008). Hasil penelitian ini sejalan dengan Studi yang dilakukan wiyono (2008) terhadap para wajib pajak yang telah mencoba menggunakan e-filing di indonesia telah menunjukan hasil bahwa persepsi kemudahan berpengaruh signifikan terhadap persepsi kegunaan tekhnologi. Jika pengguna menginteroretasikan bahwa sistem $e$-filing mudah digunakan maka pengguna sistem akan tercapai.

Tingkat kerumitan E-filing merupakan salah satu yang menentukan keinginan wajib pajak untuk menggunakan E-filing sebagai sarana penyampaian SPT secara online dan realtime. Konsep kerumitan (complexity) ini mirip dengan konsep kemudahan (Perceived ease of use) yang dikembangkan oleh Davis et al. (1989) dalam model penerimaan TAM (technology acceptance model). Menurut davis (1989) kerumitan adalah kebalikan dari kemudahan digunakan persepsian (perceived ease of use) tersebut dapat dinyatakan bahwa jika kerumitan suatu sistem kecil yang dalam penelitian ini Efiling, maka kemudahan pengguna semakin besar serta keinginan penggunaan untuk menggunakan E-filng semakin besar.

Hasil penelitian ini sejalan dengan penelitian yang dilakukan susanto (2011) yang menyimpulkan bahwa persepsi kerumitan penggunaan memiliki pengaruh negatif terhadap persepsi kegunaan. Yang artinya sebagian besar dari wajib pajak badan yang menggunakan e-filing merasa bahwa penggunaan e-filing memudahkan dan mempercepat wajib pajak dalam menyampaikan SPT. Hasil ini juga konsisten dengan persepsi kemudahan, dimana wajib pajak badan merasa bahwa E-filing mudah digunakan, artinya E-filing tidak rumit.

\section{SIMPULAN DAN SARAN}

\section{Simpulan} berikut:

Berdasarkan hasil penelitian dan analisis data, dapat diambil simpulan sebagai

1. Perilaku wajib pajak berpengaruh positif dan signifikan terhadap persepsi kegunaan dalam penggunaan e-filing sebagai sarana pelaporan pajak secara online dan realtime pada Kantor Pajak Pratama Makassar Selatan. Hal ini berarti bahwa semakin berguna/bermanfaat sistem-efiling, maka semakin banyak Wajib Pajak yang akan menggunakan sistem tersebut.

2. Perilaku wajib pajak berpengaruh positif dan signifikan terhadap persepsi kemudahan dalam penggunaan e-filing sebagai sarana pelaporan pajak secara online dan realtime pada Kantor Pajak Pratama Makassar Selatan. Hal ini berarti bahwa semakin mudah sistem e-filing digunakan, maka semakin banyak wajib pajak yang akan menggunakan sistem tersebut.

3. Perilaku wajib pajak berpengaruh negatif dan signifikan terhadap persepsi kerumitan dalam penggunaan e-filing sebagai sarana pelaporan pajak secara inline dan realtime 
pada Kantor Pajak Pratama Makassar Selatan. Hal ini berarti bahwa semakin rumit suatu sistem maka semakin sedikit wajib pajak yang menggunakan sistem tersebut.

\section{Saran}

Hasil penelitian ini diharapkan mampu mendorong peneliti-peneliti selanjutnya untuk mengembangkan kembali hasil penelitian ini. 


\section{DAFTAR PUSTAKA}

Davis, F.S. (1989). Perceived Usefulness, Perceived Ease of Use, and Acceptance of Information system Technology. MIS quartery Vol.13, No $h$ 319-339. Universitas of Minessota

Departemen Keuangan RI. Peraturan Menteri Keuangan Republik Indonesia Nomor 192/PMK.03/2007 Tentang Tata Cara Penetapan Wajib Pajak Dengan Kriteria Tertentu Dalam Rangka Pengembalian Pendahuluan Kelebihan Pembayaran Pajak.

Direktorat Jendral Pajak RI. 2008. UU No 36 Tahun 2008.www.paja.net/blog/peraturan/UU-36-2008.pdf.diakses tanggal 11 Oktober 2012

Jogiyanto. (2007). Sistem Informasi Keperilakuan. Andi, Yogyakarta

Setiaji, dan Amir. (2005). Majalah Berita Pajak.

Siti Kurnia Rahayu, 2010. Perpajakan Indonesia. Yogyakarta : Graha Ilmu.

Susanto, Nugroho A. 2011. "Analisis Perilaku Wajib Pajak Terhadap Penerapan Sistem E-filing Direktorat Jendral Pajak. Tesis Universitas Indonesia. Jakarta

Thoha, Miftah. 2004. Perilaku Organisasi : Konsep Dasar dan Aplikasinya. Jakarta: Raja Grafindo Persada.

Undang-Undang Nomor 6 Tahun 1983 Tentang Ketentuan Umum dan Tatacara Perpajakan sebagaimana telah diubah dengan Undang-Undang Nomor 16 Tahun 2009

Wulandari. 2016. Pengaruh Penerapan E-filing, Tingkat Pemahaman Perpajakan Dan kesadaran Wajib Pajak Terhadap Kepatuhan Wajib Pajak di KPP Yogyakarta.

Walgito, Bimo. 2003. Psikologi Sosial. Yogyakarta: Andi Yogyakarta

Waluyo \& Ilyas, Wirawan B. 2003. Perpajakan Indonesia. Salemba Empat, Jakarta. Rineka Cipta

Waluyo, 2007, Perpajakan Indonesia, Buku 1 Edisi 7, Penerbit Salemba Empat, Jakarta.

Wiyono, Adrianto Sugiarto. 2008. "Evaluasi Penerima an Wajib Pajak terhadap Penggunaan E-filling sebagai Sarana Pelaporan Pajak secara Online dan Realtime. “ Jurnal Riset Akuntansi Indonesia, Vol. 11, No. 2, h. 117-132. 